\title{
The Basic Elements of Community Mental Health Education
}

\author{
Thomas J. Powell, D.S.W. \\ John M. Riley, Ph.D.
}

\begin{abstract}
An adequate plan for community mental health education should include consideration of five basic elements which are derived from an examination of the core concepts of community mental health. These five elements are approached from the vantage point of the conceptualizations and skills necessary for practice in community mental health. Illustrations of these elements are offered along with some suggestions about relevant field experiences and conceptual tools.
\end{abstract}

If community mental health is to shed the appearance of an occasional bandwagon and take on the character of a broadly based new approach, the professions must educate graduates who can shape, implement, and rationalize its ideology. Ideology alone is insufficient unless it is supported by empirically validated conceptualizations and transmittable skills and the professions must provide these in their community mental health educational programs. Moreover, these programs must have sufficient capacity to supply an adequate number of personnel.

If these ends are to be accomplished, existing educational programs are likely to be the primary resource for meeting the manpower requirements. Too few students can avail themselves of post-professional programs which would appear to be the only feasible alternative to existing programs. Moreover by the time the advanced level is achieved, many students will have acquired trained incapacities that interfere with their ability to benefit from a program involving major revisions of existing mental health practices. The knowledge and manpower requirements are simply too great for community mental health to be the domain of a particular profession or the exclusive concern of advanced educational programs. Therefore, each profession must assume responsibility for education in community mental health.

However, a multilevel and multiprofessional commitment to community mental health education will be adequate only if it is based on a sound edu-

The authors are grateful to Sydney Bernard, Harvey Bertcher, Frederick Cox, Jesse Gordon, Henry Meyer, Eugene Litwak, and Dorothy Schroeder for their helpful comments on an earlier draft of the paper.

Dr. Powell is Assistant Professor, School of Social Work, University of Michigan and Coordinator of Consultation Programs at the Washtenaw County Community Mental Health Center, Ann Arbor, Michigan. Dr. Riley is Associate Professor, School of Social Work, University of Michigan, Ann Arbor. 
cational plan. The major thrust of this paper is to suggest that community mental health must provide coverage of five basic elements. This paper is not meant to be a detailed account of any one of these elements but rather a discussion of the essential elements of an educational program that aims to prepare community mental health practitioners.

The five basic elements emerge from an examination of the core concepts of community mental health. They serve to define the boundaries which set community mental health apart from traditional clinical activity and distinguish it from other forms of community practice. Considerable agreement has been reached in identifying the core concepts (Baker \& Schulberg, 1967). The following list is intended to provide a perspective or a frame of reference for later consideration of the basic elements of a community mental health educational program.

I) Population Focus. This concept refers to an attitude of active responsibility for all segments of a catchment area population requiring some kind of mental health intervention. It has generated efforts to create services geared to high risk segments of the population. A population focus proscribes the usual practice of providing a predetermined service to a vaguely defined population "who can benefit from it."

2) Effective Manpower Utilization. Community mental health practitioners have recognized and accepted the growing imbalance between professional resources and demands. Repeated and wasteful diagnostic and referral procedures have been discouraged and continuity of care procedures across programs have been promoted as methods of more efficiently utilizing staff. Extensive efforts have also been made to capitalize on the manpower resources of the community's informal care givers by providing them with consultation, education, and access to resources.

3) Prevention. Through close association with public health, community mental health has been sensitized to opportunities for primary prevention. Thus, programs to modify pathogenic community conditions are placed alongside programs offering treatment to individual patients. This, of course, represents a significant departure from the clinician's nearly exclusive concern with secondary and tertiary prevention.

4) Diverse Methods and Intervention. This concept suggests that various kinds of intervention may be relevant for different kinds of mental health problems. The community mental health practitioner values a series of interventions including, social, educational, economic, somatic, and psychotherapeutic approaches to problem resolution.

5) Multiple Levels of Intervention. The individual, the group, the organization, and the community may be thought of as equally appropriate intervention targets for community mental health practitioners. This concept stimulates consideration of the complementarity and relative potency of the different levels of intervention.

\section{THE BASIC ELEMENTS OF COMMUNITY MENTAL HEALTH EDUCATION}

When considering an educational plan, the above concepts suggest certain basic elements in an adequate community mental health curriculum. The formulation of these elements of community mental health education has been informed and stimulated by the work of others who have pointed up the inadequacy of existing professional education for community mental health practice (Baler, 1967; Hassler, 1965; Wittman, 1958). The discussion to follow sets out five basic elements from the vantage point of the conceptualizations and skills necessary for practice in community mental health. 


\section{Community Structure and Process}

The immediate task of a community mental health program is to acquire and maintain community legitimation and thus secure its domain. Systematic pursuit of this task requires a knowledge of the power bases that influence the decision making processes in the community. Without the ability to assess available opportunities and constraints and without the capacity to predict the consequences of its actions on other formal and informal community organizations, the agency will be unable to mount a viable and coherent program. Many communities, for example, may exhibit more tolerance for innovative services to schools than for services specifically targeted to the poor segment of the population.

A larger task for the agency is the assessment and modification of conditions that are associated with a high rate of mental disorder. This requires a knowledge of the relationship between such factors as marital status, socioeconomic status, mobility, age, sex, and mental disorder and the cumulative nature of their impact on the individual. Such knowledge may then require direct work with an industrial or agricultural organization that is a focal point for individuals who are known to have a high risk for mental disorder. The attempt to alter pathogenic conditions is likely to necessitate modifications in some of the major regulating institutions. Thus the practitioner is confronted with problems of entry and change strategy as he interacts with institutions such as social welfare, health, industry, education, and the legal-correctional system.

A variety of social science conceptualizations and field experiences constitute relevant preparation for these tasks. On the one hand there is the literature concerned with the epidemiological distribution of disorders in the population (Monroe et al., 1967). On the other hand, a rapidly expanding body of knowledge relates to the various regulating sub-systems in the community and to the community itself as a social system (Warren, 1963). Increasingly, methods are being developed to analyze and intervene within these systems. Relevant field experiences abound though they may not be explicitly related to the tasks of community mental health. One such class of opportunities exists in the numerous planning bodies that are a part of most of our larger communities.

\section{Integration of Mental Health and Social Welfare Resources}

Because of its population focus, community mental health programs cannot escape responsibility for the coordination, development, and integration of relevant services. But this obligation combined with the fact of its own membership in this sub-community places the community mental health agency in a potentially competitive and threatening relationship to other agencies and private practitioners. The situation is par- 
tially analogous to that of the health and welfare councils whose success as a coordinating mechanism has been far from spectacular. Undoubtedly community mental health will have to contend with some of the same problems which arise from a mission that lacks specific or sufficient legitimation and power.

Success in this area will depend on the development of conceptual tools for dealing with the problems of bringing about an orderly network of services. These tools are most likely to be acquired from the theories related to community and formal organizations. Particular attention will have to be given to the structure of the mental health sub-community and to its patterns of alliance and inter-organizational exchange (Levine \& White, 1961). Students can begin to develop skill in these areas by participation in the numerous exchanges which occur between a community mental health program and other agencies when new organizational arrangements are being considered. Another source of this experience can be found in the many agencies that have a high level of exchange with external organizations. Some of the best field experiences may be found outside the mental health field, in the large number of agencies concerned with the improvement of inter-group relations and the development of human opportunity.

\section{Organizational Structure and Process}

Identification of this area tends to make more visible the internal structures and process that may have a profound impact on the effectiveness of an organization. In the case of community mental health, the problem is more complicated because of its multiple activities and the diverse nature of its intermediate goals. The many activities and different program objectives require an interdisciplinary staff which intesifies the strain between professional and bureaucratic authority. The dilemmas facing the administrator are sharpened further by the continually changing nature of the community mental health programs which place a premium on the ability to planfully manipulate organizational variables in order to enhance agency effectiveness. The local sponsorship of many community mental health agencies increases the burden of monitoring the organization's activity to ensure that it is responsive and accountable to the local community.

A rapidly expanding body of theory and empirical findings in the area of administration and formal organizations can serve as a conceptual base for developing the skills to perform these tasks (Thompson, 1967). Many agencies, some new and others undergoing major revision, are involved in a struggle to develop adequate organizational structures for integrating their internal activities and managing the demands of their environment. They frequently offer unusual opportunities for students to confront many of these issues. 


\section{Direct Services}

Direct services refer to the immediacy of contact between the professional and his client group. Clinical skills are highly useful in this context, and for this reason can serve as a bridge for those who wish to make the transition between clinical and community mental health practice.

The community mental health practitioner is distinguished by his concern with the impact of his efforts on overall prevalence rates for mental and related disorders in the population. Precisely because of its limited impact on community rates, there has been a shift away from long-term intensive treatment to more selective patterns of intervention. Crisis theory provides a rationale for this shift in that it identifies a large number of developmental and situational crises which constitute leveraged opportunities to maximize therapeutic benefit (Parad, 1965).

However crisis intervention is only a partial solution. Many individuals in need of help do not contact the mental health professional and even if they did there would not be a sufficient number of professionals. Moreover crisis intervention is not an adequate response to the many disorders, chronic and degenerative in nature, which require more basic socialization approaches. These findings have prompted a variety of efforts to improve the help offered by the community's natural care givers. Consultation has been one of the chief methods used to assist such natural care giver groups as teachers, nurses, family doctors, and clergy (Caplan, 1964). Similar efforts to extend services have led to the creation of new career positions, particularly for indigenous persons who may perform as counselors, client advocates, and organizers (Riessman, 1967).

Because of its proximity to clinical practice a vast array of conceptualizations and field experiences are potentially relevant. Any list of the potential borrowings would have to include such content as, dynamic psychology, human development, learning theory, group dynamics, and therapeutic methods. Appropriate field experiences may be found in those agencies which give an important place to brief treatment, natural care givers, and nonprofessionals in their treatment programs.

\section{Planning and Evaluation}

Planning and evaluation are integral components of a continuous cycle of program development, implementation, refinement, and the development of new programs. Initially every community agency must investigate the needs-resource balance in the target population. Such a plan leads to the identification of high risk groups and high risk areas which have priority for interventive programs. The monitoring of program operations provides a useful source of data for new program planning. In addition, more basic investigations are needed of the largely untested programs of crisis intervention, consultation, and community development which are characteristic of community mental health agencies. 
Educational preparation for these tasks may be found in the theories of social planning and community development (Morris \& Binstock, 1966). Technical skills may be acquired from the study and practice of research methods particularly when they are carried out in the context of evaluative and epidemiological investigations. Appropriate field experiences are available in the growing number of research and planning agencies or their counterpart divisions in other agencies.

\section{SUMMARY AND CONCLUSIONS}

An examination of selected community mental health concepts suggests that an adequate educational program should contain five basic elements. These elements have been discussed in terms of the conceptualizations and skills necessary to intervene at levels ranging from the large scale community to the single individual. An adequate educational program, it is argued, must consider the relevance of each of these components to community mental health problems. While individual practitioners and even individual professions may develop primary competence in one or more of these areas, it is assumed that exposure to all five elements is necessary to gain an appreciation for the integrity of community mental health.

As noted earlier, community mental health content must be brought into the basic educational programs of the professions. Examination of these elements reveals numerous links with current curricula and does not compel radical overhaul of existing educational programs although, realistically, additions to many programs will be necessary in order to achieve adequate coverage. Yet much current content is potentially relevant provided explicit reference is made to the linkage between this content and community mental health.

Nonetheless the simple idea of reconceptualizing existing curricula should not be mistaken for a prediction about its ease of accomplishment. Implementation of this idea would require a more equitable distribution of educational resources among the basic components than now exists. More fundamentally it would require a realignment of the priorities reflected in existing educational programs for mental health professions. In this respect the task is not dissimilar from the larger task of community mental health to revise the basic pattern of mental health services.

\section{REFERENCES}

Baker, F., \& Schulberg, H. C. The development of a community mental health ideology scale. Community Mental Health Journal, 1967, 3, 3, 216-225.

Baler, L. A. Training for research in community mental health, Community Mental Health Journal, 1967, 3, 3, 250-253.

Caplan, G. Principles of preventive psychiatry. New York: Basic Books, 1964. 
Hassler, F. R. Psychiatric manpower and community mental health: A survey of psychiatric residents. American Journal of Orthopsychiatry, 1965, 35, 695-706.

Levine, S., \& White, P. Exchange as a conceptual framework for inter-organizational relations. Administrative Science Quarterly, 196x, 5, 583-601.

Monroe, R., Klee, G., \& Brody, E. (Eds.) Psychiatric epidemiology and mental health planning. Psychiatric Research Report No. 22. Washington: American Psychiatric Association, I967.

Morris, R., \& Binstock, R. Feasible planning for social change. New York: Columbia University Press, 1966.

Parad, H. (Ed.) Crisis intervention. New York: Family Service Association, 1965.

Riessman, F. Strategies and suggestions for training nonprofessionals. Community Mental Health Journal, 1967, 3, 2, 103-110.

Thompson, J. Organizations in action. New York: McGraw-Hill, 1967.

Warren, R. L. The community in America. Chicago: Rand-McNally, 1963.

Wittman, M. Education for community mental health practice. Social Work, 1958, 3, 64-70.

ROLES FOR OLDER PEOPLE-PROSPECTS FOR THE '7os-is the theme of The University of Michigan's 23rd Annual Conference on Aging, August 12-14, 1970.

The broadest possible participation is being encouraged by older people who will present the challenge to the conference and by leaders from social welfare organizations, government, educational institutions, industry, labor, community planning agencies, religious organizations and many kinds of professional and technical groups who will share responsibility for identifying the major issues in aging to be resolved in the 1970's and discussing mechanisms for shaping a better life for America's older people.

As a special feature of the conference, the 35th anniversary of the passage of the Social Security Act will be celebrated by distinguished national leaders who will review the beginnings of social security in this country, assess its achievements, and discuss its promise for the future of America's older people.

For further information about the conference write to Woodrow W. Hunter, Acting Co-Director, Institute of Gerontology, 1021 E. Huron Street, Ann Arbor, Michigan 48104. 